\title{
From blueprint to action: The transformation of the planning paradigm for desakota in China
}

\begin{abstract}
With a case study of Chaonan in Guangdong Province, this study examines China's desakota and its planning paradigm. After three decades of high-speed growth, the marginal areas of Guangdong Province - the lab of China's market-oriented reform and open door policy, are still fraught with desakotas, semi-urbanized areas of mixed landscape, economic and administrative systems. Chaonan faces a number of challenges, such as economic slowdown, poor infrastructure, environmental pollution, and so on. We found that China's desakota is driven by decades of rural industrialization, and this is now becoming a major challenge to master planning, the paradigm of which mainly comes from the rational theories of early western countries. As the traditional paradigm emphasizes the overall blueprint, there is a mismatch between planning orientation and spontaneous investment demand. Planning implementation thus is almost impossible. As such, we take the master plan of Chaonan as a case to integrate both blueprints and actions. To turn traditional blueprint-led planning into action-led planning, we highlight both recent and long-term actions, to make practical improvements to various facets, socio-economic upgrading, socio-spatial transformation, and environmental sustainability. Above all, we argue that action-led planning is the key to the transformation of desakotas in China.
\end{abstract}

Key Words: Desakota, planning paradigm, master plan, China

Acknowledgements: This study is supported by the National Science Foundation of China (NO. 51578276, No. 41422103). We appreciate the critics and comments of an earlier draft of this piece by Professor Jieming Zhu of Tongji University and Professor Jingxiang Zhang of Nanjing University. 


\section{Introduction}

Against the emergence of planetary urbanization (Brenner, 2014), the endless expansion of capitalism, and the faster mobility of people, goods and information, recent urban studies further highlight the complexity of contemporary urban spaces (Brenner \& Schmid, 2014), as captured by such terms as scaling (Savitch, 2010), assemblage (McFarlane, 2011), informality (A. Roy, 2005), and so on. Among them, the ideas of neocolonialism, comparative urbanism (McFarlane \& Robinson, 2012), or 'worlding' cities (Roy \& Ong, 2011) indicate the significance of producing or revising sitting urban theories, mainly based on the experiences of Western developed countries, through in-depth examinations of cities in the global South (Robinson, 2002, 2005), the major sites of existent urbanization (Criqui, 2015; Shatkin, 2011). In this vein, this study contributes to the literature by examining planning and its dilemma in Chaonan, a marginal city in Guangdong Province - China's market-oriented reform and open door experiments (Lin, 2001). We argue that, differing from 'formal' space of urban China, Desakota such as Chaonan are mainly driven by the mechanism of rural industrialization (Shen, 2006), which subsequently poses as a major challenge for master planning, the paradigm that mainly comes from the rational theories of early western countries (F. Wu, 2015). We will interrogate the transformation of the planning paradigm of Chaonan from blueprint to action, and take it as a case to show the reasons why the traditional planning paradigm cannot work against the context of desakota. We will propose possible resolutions for the implementation of planning.

The contents will be organized as follows. First we review the study of desakota and highlight the difficulties for traditional planning to serve its developments. We will also examine the changing planning paradigms of post-reform urban China and link them to discussions on desakota transformation and planning. After that, we will examine Chaonan and interrogate the failure of the traditional planning paradigm - the blueprint plan applied to the area, i.e. the Master Plan 2003. Moreover, we apply a new paradigm of action planning in Master Plan 2013, and take it as a way to fight against the 
challenges of planning, so to transform desakota areas in China or other developing countries.

\section{Desakota and its challenges to the planning paradigms of post-reform China}

The term Desakota, first proposed by McGee $(1991,1998)$, indicates a special urbanization phenomenon in developing countries and regions such as Indonesia, Thailand, India, and China. Following the notions of urban fringe, edge city, extended metropolitan region and so on, desakota presents a large number of features differing from those of traditional cities. In details, the main features of desakota include dense population, farmers, rice cultivation, and decentralized management style; the original center of the city's outward diffusion of industrial development into rural areas; the formation of non-agricultural industries; a variety of land uses for agriculture and nonagriculture with staggered layout; persons and goods within the region having strong fluidity and mobility; and the informal sector being widely spread. In recent decades, desakota has been applied worldwide to examine areas of mixed urban and rural features, especially in developing countries (Xie, et al., 2007). Against different contexts, the modalities or development dynamics of Desakota may be diverse, yet the challenges to further development have been noted.

The spread of Desakota in developing contexts such as China, thus composes a challenge to the theory or applications of urban planning (Watson, 2013), as the cities of the global 'South' or 'East' have different characteristics to the 'North', where most of the planning theories originated from. Criqui (2015) proposed an idea of 'infrastructure urbanism' by examining the deficiencies of planning in developing contexts such as Delhi and Lima. The lack of planning is not an obstacle to serving desakotas; rather, social, commercial and technical innovations have helped to extend the coverage of infrastructures, together with institutional creativity and bricolage, compensating for the inadequacy of planning. 
Watson (2009) argued that the study of the global South can be useful in unsettling 'taken-for-granted' assumptions in planning theory. There is a 'clash of rationalities' between techno-managerial and marketized systems of government administration, service provision and planning, i.e. the North, and those urban populations surviving largely under conditions of informality, i.e. the South. Such post-colonialism ideas indicate that the studies of planning in global South may contribute to the renovation of existed planning theories.

\subsection{Desakota: the space of informality in post-reform China}

Some regions in China are typical desakotas (Zhu and Guo 2014; Y. Zhou \& Ma, 2000). Ginsburg (1998) argued that Guangzhou and Shenzhen, as the center of the Pearl River Delta, are the Chinese version of a desakota. He summarized the desakota model as a mixed spatial system (Fig. 1). Sometimes it is regarded as a 'bottom-up' type of urbanization (Shen, et al., 2006) or the urban-rural fringe. In this particular space, economic activity, social activity, and life service show both urban and rural features. For example, Zhu and Guo (2014) examined a typical desakota region in Nanhai, Guangdong, where they found that the urban and rural integration strategy hindered the improvement of urbanization. Sit and Yang (1997), however, argued that though the characteristics of PRD were consistent with McGee's desakota model (Tab.1) in many ways, there were still significant differences, such as rural migrants, state power and other aspects. Nevertheless, scholars agreed that the urbanization process in desakota is much more special and challenging than in other areas, and the governance of desakota is far more complicated.

[Figure 1 and Table 1]

The development of Desakota in China dated back to the late 1970s. After the implementation of market reform and open-door policies, the central government 
curbed the development of large cities, while the development of small towns was encouraged (Walder, 1995), thereby enabling small towns to play major roles in the urbanization process of China (Ma \& Cui, 2002). However, new changes appeared in the 1990s. The construction of development zones started across China and industrial zones became the main power of industrialization (D. Y. R. Yang \& Wang, 2008). Some zones grew to be satellite towns and eventually new cities, with real estate taking the place of industry. In PRD, a transition of urbanization

from bottom-up to top-down happened (Shen, 2006). However, Desakota areas retained the old urbanization model and missed the opportunity of upgrading, so that they are still characterized by informality.

First, when small industries upgraded to industrial parks and larger-scale manufacturing, desakota areas retained private, small or even family-based manufactory. Small private industry owners play a dominant role in economic activities. In Shantou, a large city at the peripheral of Guangdong Province, for example, a special type of house, the socalled 'three-in-one' (industry + business + living) flourished. Local people who started up in business used the first floor as their small workshop and office, and the upper floor as their living area. This economy helped local people become rich and turned the rural economy into basic manufacturing; it also fragmented the form of the local economy, directly impacting the economy and social structure of Shantou (Fig.2).

[Figure 2]

Secondly, the social form of desakota appears with a self-organized character. Informal organization is responsible for local affairs in desakotas (Choy, et al., 2013). Familybased economic and social networks are interwoven together. The lasting traditional culture made social networks even tense. In villages or communities, there are special organizations called 'senior people committees' which influence both ordinary residents 
and private businessmen. This bottom-up organization becomes the de facto administrative unit of desakota areas.

Thirdly, fragmented economic and social forms have resulted in poor financial situations and public facilities. Family- or community-based social structure is self-organized. This system puts most small enterprises in an uncontrolled situation. The local government cannot raise enough taxes from local enterprises, so the quality of public infrastructure and services is poor, and the quality of urbanization is low. Economic, social and spatial structures become fragmented. The failure of governance indicates that desakotas appear to be out of control. As a result, planning also falls into a confused situation. Desakota not only indicates the spatial form, it also underlines the informal governance.

\subsection{The failure of the traditional blueprint plan for Desakota}

Traditional planning paradigm in post-reform China is marked by the blueprint plan. Against the context of high-speed growth since 1980, Chinese governments, both central and local, played a leading role in the production of space. Low-cost land resources became the engine for local development (Xu, et al., 2009). Increasing demand for urban construction land exerts pressure on the city to expand its urban boundary. Landcentered development strategy satisfied the demands of local governments (Zhu, 2013). Modern planning theories took over planning practices, and blueprint planning became the mainstream paradigm. Planners with modernist architecture backgrounds played a leading role in the professional fields of post-reform China. Accordingly, as modernist planning theory shaped China's master planning over the last decades, physical spacebased blueprint planning became the major methodology for producing China's new space. Based on the normative theory of design, the blueprint plan often focuses on environmental design. The underlying logic is linked to the growth-led regime of postreform China, which is 
marked by intensive local competition. To achieve a successful promotion, local officials often resort to economic performance or identifiable place making, which are the key indicators of political achievements. Growth-led development ideology is also closely linked with spatial beautification and (post)modernism aesthetics. Furthermore, local officials often use brilliant blueprints to attract investors, present potentials for growth, and show off their political ideals (F. Wu, 2015).

In the 1990s the trend of blueprint planning was further enhanced. Built on blueprint theory, more industrial studies were added to master planning. Though diverse planning ideas appeared in this period, and the central government started to emphasize the social, economic and pro-environment development, the growth-led blueprint planning was still the main methodology. Local economic growth remained the most important issue in the strategy of most cities or the top concern of mayors. Ambitious local economic growth thus became the key issue of the master plan. As a supplement to the traditional master plan, new paradigms such as concept plan or strategic plan appeared (F. Wu, 2007; F. Wu \& Zhang, 2007). Above all, against the background of a high-speed growth, the blueprint master plan remained the main approach for local government to apply its ambitions for economic development. Nevertheless, the application of the blueprint planning paradigm to desakota is problematic.

The development route of post-reform China is marked by path dependency, i.e. it is based on a cheap and low quality labor force, low-cost land use, high-speed industrialization, etc. In this vein, the premise of the traditional blueprint planning paradigm of China is also path-dependent, as its implementation or application is largely based on these factors. At the early stage of market reform, these factors provided advantages for local development, so that its investment-driven regime achieved success. After the tax reform in 1994, local governments expanded local tax sources, largely through business taxes and land finance income. In this vein, the paradigm of the blueprint plan is efficient and feasible, due to its power in terms of 
large-scale land use or sale. However, in the last decade, rising labor costs, limited land resources, and enhanced environment regulations have made it difficult to maintain the investment-driven regime. There is a mismatch between the new modality of development and the blueprint planning paradigm, which is particularly evident in desakotas.

Firstly, labor costs rose rapidly that labor forces could not maintain a competitive advantage in desakotas. For instance, in terms of the rise of labor costs of PRD the annual salary growth was $4.43 \%$ in 1994-2004, but in 2004-2012 the rate of increase reached $22.92 \%$ (C. Zhou, et al., 2013). The rise in living costs as well as consumption further reduced the advantages of these regions; it has been difficult for local companies in PRD to recruit new workers. Secondly, the shortage of land supply has become a serious challenge in desakotas. Historically, land resources were largely used in inefficient ways, so now there is little land to be used. Fragmentation is the marked feature of desakota: the land uses of such areas are excessively mixed, the spatial form of land use is divided into pieces, and the ownership of land is complicated. All of these make the future development difficult, and the former regime of growth is not appropriate.

Third, the traditional economy of the desakota could not continue to support the rapid industrialization of Chaonan. Though there are a number of large companies in Chaonan, most local industries still maintain a traditional yet informal management approach. The speed of economic growth is slowing down. Compared with other urban or rural areas, the governance system of desakota is specific. Social forces and the informal economy in desakotas have a strong influence on local affairs. It is hard for the local government of Chaonan to act in the same way as other powerful Chinese local states. 
For these reasons, it is hard to implement traditional blueprint planning in desakotas such as Chaonan. There should be a transition of the planning paradigm from blueprint to match the new conditions. Although the old regime of bottom-up growth has gained remarkable economic achievements, a new stage of efficient development is needed to actualize in-depth urbanization. For Chaonan, it is important to input a new planning paradigm to achieve a spatial fix along with social, economic, and institutional reconfiguration or upgrading.

\section{From blueprint to action: the transformation of planning paradigms for Desakota}

We call for the transformation of the planning paradigm for desakota from blueprint plan to action plan, and link this to the debates on the transformation of China's planning theory (F. Wu, 2015). Created in the 1960s, the action plan was defined as the solution to problems at the local level. The highlighting of the local level is linked to the transformation of capitalism, from Fordism to post-Fordism (Jessop, 1994). New changes such as the uncertainty of the market economy resulted in criticism of traditional planning, especially of the blueprint planning paradigms (Naess, 2015). For example, most blueprint plans focus on a final long term vision, whilst new paradigms such as contingent plans turned to emphasize the phasing of policy, the decisionmaking process and the implementation of planning (Naess, 2015).

John Friedman (1987) regarded 'implementation' as the key issue in urban planning, since in planning literature practice did not get enough attention compared to planning theory. Improving the effectiveness of planning became one of the key topics in the west, and the concept of the 'action plan' was widely recognized, i.e. the implementation oriented planning process that solves problems at the local level. A new trend appeared to articulate the connection and integration between planning and action. The practice movement in planning theory focused on the activity of planning and the practices of planners. It is highlighted that empirical accounts of planning practice can help to build a 
pragmatic kind of planning theory (V. Watson, 2002).

The theory of the action plan has had wide applications in the planning of the UK and the US since the 2000s. From 2001, the Single Local Development Framework (LDF) began to replace the traditional structure planning and local planning in the UK. When adopted, the Framework together with the Regional Spatial Strategy formed the statutory Development Plan for an area ${ }^{1}$. An Action Area Plan (AAPs) was proposed as a part of the LDF, focusing on specific areas that needed construction or transformation. The connection between physical planning and social economic development planning was emphasized. The AAP is a practical, manageable, and flexible document, which is not a blueprint for development but rather a guidance to the implementation of its objectives². Moreover, the AAP can be either compiled independently or be added to existing planning.

The action plan was also implemented as a component of urban planning in major cities in the US. Some were reflected in the comprehensive planning of the city such as 'PlaNYC 2030: A Greener, Greater New York', which proposed 127 initiatives specifically in ten areas of interests, including Housing and Neighborhoods, Parks and Public Spaces, and so on ${ }^{3}$. Some built upon the area plan such as the 'Chicago Central Area Action Plan 2009-2010', which contains information intended to encourage the implementation of policies and projects essential for the Central Area's effective functioning, growth, and quality of life ${ }^{4}$.

\footnotetext{
${ }^{1}$ Millbay and Stonehouse Area Action Plan 2006-2021, Plymouth City Council Department of Development, 2010.

${ }^{2}$ City Centre and University Area Action Plan 2006-2021, Plymouth City Council Department of Development, 2010.

${ }^{3}$ PlaNYC 2030: A Greener, Greater New York, New York City, 2007.

${ }^{4}$ Chicago Central Area Action Plan 2009-2020, Chicago Plan Commission, 2009.
} 
The action plan can be applied to a variety of settings, including infrastructure planning, environmental management, urban upgrading, settlement planning, community development, etc. Compared with the rationality of the blueprint planning, the action plan pays more attention to the planning implementation process, emphasizing practicability and public participation. It is marked by the following characteristics: it is based on the starting point but not the closing target; it is feasible and practical; it is incremental but not comprehensive; it encourages participation and collaboration; it emphasizes coordination; it is flexible; and it highlights time sequence.

In fact, as China has entered a so-called 'new norm' stage, with the annual growth ratio of GDP now just around 6\%, China's spatial production has also encountered a postgrowth period. In particular, urban renewal will take the place of new land use or construction as the dominant pattern of place making (He \& Wu, 2005; Hin \& Li, 2011; Y. R. Yang \& Chang, 2007). Along with the rise of the market as well as China's civic society, entrepreneurs and the general public have both become strong stakeholders in planning and construction. Planners in China now face a mismatch between wholesale, pure, or single blueprint plan and the complicated modality of developed areas such as desakotas. In order to implement the master plan, some cities try to combine the blueprint and a dynamic update mechanism. It is suggested that the action plan should be added to the statutory planning system, not only to the master plan but also to the detail plan, other types of planning, and so on (Qian \& Wong, 2012). For instance, Shenzhen is the pioneering Chinese city that has applied the concept of the action plan to its planning system. Due to the demands of its advanced development, investment and marketization, Shenzhen put efforts to integrate an action plan into its planning ideas in the last decade. Lately, other cities such as Ha'erbin and Guangzhou have also started to revise their traditional paradigm and apply action plan approaches. Such explorations indicate the significance of action plan paradigms for China's new stage, as planning now has to design a better framework for the blueprint as well as the way to achieve the 
destination step by step. Chinese planners now pay more attention to the projectoriented, dynamic process of plan making, and strive to guide the practical process of construction.

With regard to desakota, its informal organization is the key to the implementation of master plan. It is important to change the master plan paradigm to fit governance (Fig.3). In this new paradigm, the local state should play a role to coordinate both market and public forces, balance the interests of different stakeholders, and workout key agreements for the achievement of long-term goals. In short, it is not only a long-term vision, it is also a red line to protect the core resources for the city as a whole. Government will coordinate with entrepreneurs to seek investments, yet together with the public forces such as residential committees or senior residents.

[Figure 3]

Local governance is one of the keys to master plan feasibility. The blueprint plan emphasizes the future of the city. However, the action plan emphasizes who will implement that plan and how to realize the vision in a strategic way. Therefore, it is important to make it clear 'who' will complete the 'action'. An action-led master plan should carefully point out the potential stakeholders who will fulfill the actions. The stakeholders in action normally include the government, entrepreneurs (large enterprises and the informal economy sector) and the local community. In fact, it is hard to clearly draw a boundary between these stakeholders, but it is still possible to distribute them the tasks.

First, the local government should play a role as coordinator. Government should represent the public to solicit for support from high-level government for strategic or large actions, for example, environmental protection and regional infrastructure 
constructions. Moreover, government also needs to coordinate enterprises, the informal economy sector, and the community. It should set up a good communication channel between the private and public sectors. Secondly, large enterprises should play a leading role in the action plan at a regional level. Compared to government's poor financial condition, large enterprises are usually actively involved in local construction. They prefer to invest in some public projects such as road construction and share in the benefits of the contribution in the future. The informal economy sector such as small manufacturing or companies should attend to local community action. Although they cannot provide large investment in public projects, they can still contribute for their communities, for example, by building green spaces or elementary schools. Thirdly, the local community should take responsibility for attracting or encouraging different sides to become involved in action plan implementation. The local community has a strong influence on the active economy. They may attract potential investment to support the action plan.

\section{A case study: The transformation of Chaonan planning}

Chaonan, an eastern coastal area in Guangdong province, China, is one of the seven districts of Shantou city (Fig.4). Chaonan has 596 square kilometers, and it became an independent district of Shantou in 2003. The district is about $300 \mathrm{~km}$ away from Guangzhou, and is well known as 'China's 'Textile City' .

Chaonan has long been known for its vibrant private economy. Chaonan's private sector has developed quickly after the open door policy, especially since1990. Most private companies and factories are family based. The private sector plays a dominant role in the active economy of Chaonan. In 2011, the number of local private industrial enterprises reached 4500, and they achieved seven billion US dollars of gross value of industrial output, contributing more than $90 \%$ to the local industry (China Statistics Press, 2012). However, 
most of these private companies are small in size, composed of about 10-20 staff. Some may upgrade or enlarge, but then often relocate their headquarters to Guangzhou, Shanghai or other large cities, leaving the manufacturing in Chaonan hapless. In a sharp contrast to China's northern cities, local enterprises in Chaonan are mainly private. According to official statistics, the private sector contributes more than $75 \%$ to Chaonan's local economy. At the same time, each town in Chaonan specializes in one particular product, for example Xiashan town is famous for women's underwear, Liangying Town concentrates on clothing production, and Chendian town is famous for electronic equipment.

Another remarkable feature of Chaonan is high density. The population in Chaonan is 1.36 million, of which 15 percent is non-agricultural, compared to $74.2 \%$ for Shantou city. With $1,360,000$ inhabitants throughout the 596 sq.km city region, Chaonan is one of the most crowded areas in China. There is only 0.009 hectares of arable land per capita in Chaonan, much lower than the FAO (Food and Agriculture Organization) standard 0.053 hectares of arable land per capita. On the other hand, the long-term population density also brought about the culture of cosmopolitan and business traditions among local people. Chaonan people have migrated in huge numbers to overseas and accumulate a huge volume of wealth.

The third feature of Chaonan is the sprawl of built-up areas. The built-up area has been sprawling in a disorderly way and is mostly of poor quality, particularly along the only one or two trunk roads. Since most developments occur in former rural areas, and production activities are village-based, the boundaries between urban and rural have become more and more blurred, and land use has become more and more fragmented.

The fourth characteristic of Chaonan is the 'bottom-up' form of local governance. 
Most activities, from economic to public activities, are organized by social organizations rather than local governments. Villages, characterized by clan culture, play an important role in local activities, while the power of local government is weak due to poor local fiscal revenue. The result of such bottom-up governance, on the positive side, lies in that the demands of most residents can be considered and satisfied. On the negative side, however, the public spaces such as parks are in severe short supply, and local traffic is chaotic.

Our research methods include questionnaires, in-depth interviews, and field surveys. Firstly, we distributed 50, 50 and 200 copies of questionnaires to government staff, local entrepreneurs and local residents respectively, with effective responses of 46,39 , and 197 respectively. The distribution of the questionnaire was random, to guarantee the representativeness of the samples. Secondly, we further interviewed representatives from these three groups, including five government staff, three local entrepreneurs and three local residents. Also, in addition to the questionnaires and interviews, we made three field trips to Chaonan in 2014.

The findings include the followings. Firstly, the provision of infrastructure has lagged far behind the requirements of local socio-economic developments. On the one hand, the economic strength and population size of its small townships has exceeded some average cities of inland China. However, local infrastructure falls behind the level of China's small towns. For instance, the supply of local finance, insurance, business, education, security, health care, environmental protection and other public services are extremely short. On the other hand, there is a vacuum in terms of the management of urban and rural construction, infrastructure, and social security in selected areas. Moreover, there are only two libraries and exhibition halls in Chaonan, although local people are eager for such facilities (which can be observed from the survey: 66 percent of local residents thought public facilities were seriously 
insufficient). As for medical facilities, there are only 1.2 beds per thousand people in Chaonan, compared with 5 in downtown Shantou. People have to go to Shantou downtown, Chaoyang district or even Jieyang, distant neighbors, for these facilities. Most of the respondents have been to neighboring cities for shopping and education, as well as medical checkups. In contrast, public facilities at the community level, which are mainly provided by community/village or collectives, are sufficient, some are even oversupplied. For example, in terms of educational facilities, there are a large number of primary schools in Chaonan, and almost every village has its own primary school. .

The development of rural-based informal sectors leads to 'gray spaces' in terms of administrative management. According to our survey, about $25 \%$ of local residents deemed the 'disorder' of local construction to be a serious problem (Fig.5). Local governments have failed to control the spatial layout of Chaonan. Though the Master Plan 2003 provided the city with a structured spatial framework, the plan has hardly been put into implementation. The failure of the master plan is largely due to the poor financial situation, the private economy, and the urban-rural duality of land ownership. According to our survey, as asserted by local officials, Master Plan 2003 achieved none of its original goals, and the most difficult areas included industrial development, transportation construction, infrastructure provision and environmental protection. It has further deteriorated due to the local government's poor financial situation. As suggested by some local officials, a successful master plan for Chaonan should take the private sector and local enterprises into careful consideration. The planning of Chaonan may involve three groups of stakeholders: local governments, entrepreneurs, and public (represented by village collectives). 


\section{[Figure 5]}

In detail, local governments are short of the funding needed to afford the cost of further developments. Rather than guiding economic development, the focus of the local governments should turn to work with the other two groups of stakeholders to provide public goods. In fact, entrepreneurs as well as the private sector are active in the social and economic life of Chaonan. The private sectors contribute significantly the local community (villages or towns). For instance, a number of companies and factories donate a great deal of money to local schools and other public facilities. However, their success is based on the low cost of human resources, working as original equipment manufacturers (OEM) without any need for innovation, and pollution. A successful master plan should encourage innovation and the upgrading of local enterprises, tackling the issue of low-efficiency land use, and fighting the serious problem of environmental pollution. Thirdly, village collectives represent the interests of local residents or villagers. On the one hand, they have largely taken the place of local government in providing public goods. On the other hand, their concerns are limited to their own villages/communities, bringing about low-quality yet fragmented public facility systems. As such, a successful master plan should take the public interest into full consideration and strive to integrate the decentralized power structure.

\subsection{Blueprint planning paradigm: Master Plan 2003}

With a careful examination of Master Plan 2003 (MP2003), we could further investigate the failure of the blueprint planning paradigm for Chaonan. The poor recognition of local residents for MP2003 is indicative of the low level of the participatory involvement of the participants. For instance, only $11.5 \%$ of local residents have heard of MP2003, while less than $50 \%$ thought it has had a significant impact on their lives. MP2003 is marked by low participation of stakeholders in the planning process. Though most local residents regarded the private sector (37.69\%), rather than local government $(24.12 \%)$, as the leader of the construction and development of Chaonan, MP2003 did not take 
the private sector into considerations.

Even after about a decade of implementation, the original goal of MP2003 has not been achieved. Firstly, it saw the future of Chaonan as the 'regional logistics center and famous light industrial manufacturing city', yet the status of Chaonan is still envisaged. Local industries such as textiles or plastic products are still short in reputation or brands, falling at the low end of the industry chain (Tab.2, Tab.3, Tab. 4). Only $21 \%$ of entrepreneurs we surveyed thought that MP2003 had achieved the original goal.

Secondly, the layout of local industry has also not been completed. According to MP2003, most local factories should be relocated from villages into industrial parks. However, only $41 \%$ of surveyed entrepreneurs agreed with the idea of the relocation, and the space of the local industry is still marked by fragmentation.

[Table 2, Table 3, and Table 4]

Though the de facto inputs of local entrepreneurs have greatly impacted local development, as a matter of fact they rarely involve master planning. MP 2003 has failed in neither guiding nor constraining local development. For example, MP2003 has designed regulations for the emission of pollutants, industry layout, and so on, yet there is no mechanism to implement them. Hence the environment has been further polluted, and the chaotic spatial layout has been exacerbated. The fragmentation of land use has deteriorated. According to our survey, about $23.7 \%$ of entrepreneurs saw the poor performance of environmental protection as the top failure of MP2003, only second to the issue of improving infrastructure. The government officials were also not satisfied with MP2003. When it comes to the question, 'What do you think of the constructions in Chaonan during the past 10 years', only $17.39 \%$ of respondents from government think it is good. The most unsatisfactory aspects as most frequently rated by local officials were environmental protection, the construction of 
infrastructure, and transportation.

Subsequently, local government officials thought MP2003 had achieved none of its original goals, and the most difficult implementation areas were industrial development, transportation construction, infrastructure construction and environmental protection. Why has it been so difficult to implement MP2003? There are three dilemmas in terms of its implementation: the spatial dilemma, the public good dilemma, and the environmental dilemma.

Firstly, MP2003 faced an awkward situation in terms of the existing spatial management regime. In the last decade, the mixed use of urban and rural land has been highly intensified. That is, local construction has long been disordered. Local residents' satisfaction with their living environment is pretty low: only 5 percent of local residents are satisfied with their living environment. Most people think traveling is inconvenient, as reflected in the shortage of roads, a large number of dead-end roads, traffic jams, and so on. The use of electric cars/motorcycles further aggravates traffic congestions, as $63.2 \%$ of respondents chose motorcar/electric car as their main traffic tools. Secondly, though MP2003 provides detailed planning of public services, considering that most local construction and public facilities are provided by villages/communities, yet no strategies were set to raise funding and no clear responsibility assigned for various participants, thus planning was difficult to be implemented. The mismatch between the financial power of the collectives and local government leads to an institutional dilemma in terms of public facility provision. For instance, the overall satisfaction level of public facilities provided at the district level, i.e. urban, is low: only $23 \%$. However, at the community or village level, i.e. rural, $66 \%$ of local residents rated satisfaction with their facilities. Thirdly, the polluted environment has become a key concern of the local residents. According to the survey, over $50 \%$ of respondents are dissatisfied with the local environment, and they think the most serious environmental problems are water pollution, lack of green space, and illegal construction. 
A major problem with MP2003 is the mismatch between its planning concepts and methodology. Firstly, MP2003 has failed to include the public and private sector as well as local government officials in the creation of visions and targets, or the cultivation of common ideas. The failure of MP2003 is indicative of the failure of traditional top-down governance in Chaonan. There is a great distance between the blueprint plan and its actual implementation. Underlying the blueprint plan is an assumption that local finance could support local development or regeneration, but the actual existing poor financial capacity prevented it from actualizing this vision. Secondly, with regard to public goods such as green spaces, there is no control for resources and environment. Public goods belong to the whole region and not to a single town or a single village. The traditional plan could not workout the differences. MP2003 failed to take the actual existing bottomup mechanism of development into consideration. The planning did not meet the demands of local collectives, and therefore could not be implemented. Last but not least, as for the spatial arrangement in Chaonan, the land use plan of MP2003 could not fit the local economic organization.

\subsection{Action-led planning paradigm: Master Plan 2013}

In Master Plan 2013 (MP2013), we tried to build a new planning paradigm in several ways. MP2013 emphasizes retaining sufficient flexibility rather than a detailed blueprint. The plan provides only a developing framework, such as long-time vision, development strategies, the transportation network system, etc. Second, the plan has considered the role of different stakeholders based on an action plan. Government should be in charge of environmental protection and regional infrastructure construction, large enterprises in Chaonan should play a leading role in the action plan at a regional level, and local communities should take responsibility for attracting or encouraging different sides to be involved in the implementation. Moreover, MP2013 put 
forwards a series of micro-actions to ensure the feasibility of the plan. For example, MP2013 provides a micro-action plan which emphasizes connecting existing deadend roads and widening existing roads.

MP2013 has set up a new methodology, which emphasizes both the action plan and the reform of the blueprint plan. Though MP2013 has been implemented for just several years, positive feedbacks as well as expectations have been received. For example, local residents prefer the overall orientation and local development strategy of MP2013 to that of MP2003. About $40 \%$ of respondents thought the orientation of MP2013 was better. Moreover, MP2013 emphasizes bottom-up mechanisms rather than traditional top-down ones. According to the survey, over $44 \%$ of respondents thought that village chiefs or committees were more important than local governments, in terms of local development as well as planning.

According to government officials' feedbacks, MP2013 is much more practical than MP2003. On the one hand, it has fully taken into consideration realistic conditions, therefore the plan is practical and effective in terms of guiding local development and detailed planning (58\% of officials think MP2013 is more practical). On the other hand, besides the overall blueprint plan, MP2013 further provides a series of practical actions or projects, which were deemed as important in the master planning of Chaonan (75\% 
of official respondents approved the action plan).

MP2013 has put the effect of the private sector in the development of Chaonan into careful consideration. On the one hand, it focuses on the provision of public goods. On the other hand, as for the development of local economy, MP2013 has fully respected the local private sector. Instead of directly regulating the local industry, it focuses on providing platforms, such as the whole-industry-chain cooperation platform and the Chaonan-commerce platform, business services such as water supply and drainage facilities, community parks, and social housing. According to our interview, some local entrepreneurs mentioned that if a factory could provide a better working and residential environment, such as a street garden, even if their pay was lower than other factories, employees would rather stay there and keep working. The local government of Chaonan has long faced a lack of public finance. How to solve such problems? MP2013 put private capital into full consideration and proposed a series of strategies to sort out the problem. For instance, it called for the establishment of 'Chaoshan Bank' to attract the investments of overseas Chinese. Chaoshan is known for its long history of emigration overseas, so that there are millions of Chaonan people living in countries like the USA or Canada.

In essence, the action plan is the major feature of MP2013. To match the bottom-up development pattern of Chaonan, we designed a number of important actions at the community level. In detail, the actions include: mandatory actions; public-realm enhancements; private-sector leading; and integrated strategic actions.

Mandatory actions: To ensure the security of the ecological environment and agricultural production, MP2013 put forward a series of mandatory actions, such as a production base for safe food, the restoration of the local water system, pollution control actions, etc. 
Public-realm enhancements: There are four types of urban and rural delicate space, which include urban and rural settlements, industrial production spaces, ecological spaces, and historical and cultural spaces (Fig.6). With the impact of all of these spaces, we are expecting that surrounding spaces will also gradually be promoted and renewed.

[Figure 6]

Private-sector leading: Private-sector leading includes four types: the optimization of local transportation, the smart growth of industrial space, the regeneration of space, and the supplementing of public services (Fig.7). In order to enhance traffic capacity at relatively small cost, for instance, Master Plan 2013, proposed that, the traffic optimization of local communities should mainly take three forms: connection, expansion, and optimization. Firstly, by connecting current dead-end roads, the connectivity of the local road network could be greatly enhanced. Secondly, by widening current roads, especially arterial roads, vehicular acceleration rate could be improved. Thirdly, by replacing some unsuitable functions of current roads, especially for future arterial roads, road functions could be highly optimized.

[Figure 7]

Integrated strategic actions: This category refers to projects of great significance in the future development of Chaonan, yet they are difficult to implement in the short term, or which cannot be achieved simply by local government. This kind of projects include environmental actions such as the environmental renovation of Lianjiang River, XiashanDaxi and Liangying River, as well as the comprehensive traffic transformation of Shannan Avenue and 324 National Road (Fig.8). For these kinds of actions, development space must be reserved to coordinate with the long-term blueprint. 
According to government officials' feedback, the action plan part is welcomed by local officials. According to our survey, more than $75 \%$ of official respondents approved the action plan part, and some of them think that such actions provide local officials with a practical way to implement the master plan, especially when compared with the traditional plan, which provides only ideal goals. Furthermore, some of the actions proposed by MP2013, such as the reconstruction of 'NO 324 National Road', the planning and design of Xianmencheng village, and the comprehensive construction of Chensha Road, have already been put into implementation.

[Figure 8]

Table 5 compares MP2003 and MP2013 to highlight the differences in terms of their planning background, planning guideline, planning process, planning methodology and planning content. Against the context of a high-speed growth, MP2003 and its target is to maintain the speed of growth. Conversely, MP2013 is made with a reconsideration of long-term as well as sustainable development, in order to permit the inclusion of a number of new ideologies such as people-oriented development or sustainability. Secondly, the planning process of MP2003 is dominated by the local state, and there is insufficient public participation; in contrast, MP2013 highlights public participation across the planning process. In terms of the planning methodologies, MP2003 is marked by blueprint planning, yet MP2013 is a combination of ideal blueprint and action plan, so that the latter take a serious consideration of realistic contexts. Accordingly, as to their planning contents, MP2003 is composed of a target system aiming at highspeed growth, and most of its plan centers around physical space; differently, MP2013 further considers social, ecological, and cultural issues, and integrates both urban and rural development into the planning contents. 
[Table 5]

\section{Discussions and Conclusions}

In this study we interrogate the complicated dynamics of desakota development in a rapidly developing context, and highlight the transition of its planning paradigm from blueprint to action. In this way, we contribute to the literature by highlighting the complicated yet diverse routes of actually existing urbanism in the global South, and articulate the mismatch between its modality and the blueprint-led theory of planning based on the experiences of the North. We articulate the significance of so-called action plan, and take it as a significant strategy to fight against the dilemmas of the low-level urbanization we identified in Chaonan.

It is found that the transformation of Chaonan has been marked by the dual-track dynamics of formal and informal, top-down and bottom-up, and urban and rural. We argue that desakotas such as Chaonan fall into a dilemma of transition, so that its process of urbanization differs from that listed in traditional theories (Y. A. Yang \& Yu, 2013). Nevertheless, rather than full negativity, in this case we also see the positivity of bottom-up growth. The studies of 'urban villages' in selected PRD cities, Guangzhou, Shenzhen and Zhuhai found that these migrant communities provide important affordable housing for migrants to be integrated into these cities (Hin\& Li, 2011; Wang, Wang, \& Wu, 2009; Zheng, Long, Fan, \&Gu, 2009). In the same vein, desakotas provide important opportunities for these places to integrate into the global economy, attract investment, and accumulate labor forces, so to achieve economic takeoffs.

The status quo of the desakotas differs from that of 'formal' urbanization areas (A. Roy, 2005). After market reform, China adopted a land-centered regime to achieve 
economic growth, especially during the stage of rapid urbanization. The traditional blueprint plan became the rule for master planning in post-reform China. In contrast, desakotas could not totally match the assumptions set by traditional blueprint planning, in terms of their social, cultural and spatial modalities. The informal economic model and special governance model of desakotas make it even harder to implement blueprint planning.

In Chaonan we identify the shortcomings of blueprint planning paradigms and interrogate the problems in terms of the implementation of MP2003. Chaonan's growth regime is by no means sustainable, as its upgrading is becoming necessary or even urgent. As such, we proposed a new model of an action planning paradigm, i.e. MP2013, and put forward a series of strategies to construct an implementation-oriented framework. Accordingly, a number of projects planned in MP2013 have been successfully implemented. Our surveys of local residents, officials, and investors further confirmed the effects of these strategies.

Moreover, we found that an action plan can be further divided into different categories or subdivisions. For instance, the implementation of planning involves stakeholders such as the government, enterprises (informal economic organizations and formal enterprises), and the public (community/villagers). According to their different roles in planning, the framework can be further divided into four levels: mandatory actions, public-realm enhancements, private-sector leading, and integrated strategic actions. In all, we articulate that the key to a successful implementation of planning in the desakotas is to address the local modality of economic organization, social structure, cultural characteristics, and spatial dynamics. It is an urgent need for the desakotas of the global South to develop a new planning method which is capable of achieving a balance among residents, 
enterprises and governments.

\section{REFERENCES}

[1]. Brenner, N. (2014). Implosions/Explosions: Towards a Study of Planetary Urbanization.Berlin: Jovis.

[2]. Brenner, N., \& Schmid, C. (2014). The 'urban age' in question. International Journal of Urban and Regional Research, 38, 731-755.

[3]. Choy, L. H. T., Lai, Y., \& Lok, W. (2013). Economic performance of industrial development on collective land in the urbanization process in China: Empirical evidence from Shenzhen.Habitat International, 40, 184-193.

[4]. Criqui, L. (2015). Infrastructure urbanism: Roadmaps for servicing unplanned urbanisation in emerging cities. Habitat International, 47, 93-102.

[5]. Friedmann, J. (1987). Planning in the Public Domain: From Knowledge to Action. Princeton, N.J.: Princeton University Press.

[6]. Ginsburg, N. S. (1998). An Urbanizing World: Global Report on Human Settlements, 1996.Economic Development and Cultural Change, 47, 215-218.

[7]. He, S. \& Wu, F.(2005). Property-led redevelopment in post-reform China: A case study of Xintiandi redevelopment project in Shanghai. Journal of Urban Affairs, 27(1):1-23.

[8]. Hin, L., \& Li, X. (2011). Redevelopment of urban villages in Shenzhen, China - An analysis of power relations and urban coalitions. Habitat International, 35, 426-434.

[9]. Jessop, B. (1994). Post-fordism and the state. In A. Amin (Ed.), Post-fordism: A reader (pp. 251-279), Oxford: Blackwell.

[10]. Lin, G. C. S. (2001). Metropolitan development in a transitional socialist economy: Spatial restructuring in the Pearl River Delta, China.Urban Studies, 38, 383-406.

[11]. Ma, L. J. C., \& Cui, G. (2002). Economic transition at the local level: Diverse forms of town development in China.Eurasian Geography and Economics, 43, 79-103.

[12]. McFarlane, C., \& Robinson, J. (2012). Introduction-experiments in comparative urbanism. Urban Geography, 33, 765-773.

[13]. McFarlane, C. (2011) Assemblage and critical urbanism, City: Analysis of urban trends, culture, theory, policy, action, 15, 204-224

[14]. McGee, T. G. (1991). The emergence of desakota regions in Asia:Expanding a hypothesis. In Ginsburg,N.,Koppel,B.and McGee,T.G.,eds.,The Extended Metropolis:

Settlement Transition in Asia.Honolulu: University of Hawaii Press, 3-25.

[15]. McGee, T. G. (1998). Five decades of urbanization in Southeast Asia: a personal encounter.In Y. M. Yeung (Ed.), Urban evelopment in Asia: Retrospect and rospect (pp. 
55-94). Hong Kong: The Chinese University of Hong Kong Press.

[16]. Naess, P. (2015). Critical Realism, urban planning and urban research. European Planning Studies, 23, 1228-1244.

[17]. Qian, H., \& Wong, C. (2012). Master planning under urban-rural integration: The case of Nanjing, China.Urban Policy and Research, 30, 403-421.

[18]. Robinson, J. (2002). Global and world cities: A view from off the map.International Journal of Urban and Regional Research, 26, 531-554. [19].

[19]. Robinson, J. (2005). Urban geography: world cities, or a world of cities. Progress In Human Geography, 29, 757-765.

[20]. Roy, A. (2005). Urban informality - Toward an epistemology of planning. Journal of the American Planning Association, 71, 147-158.

[21]. Roy, A., \& Ong, A. (2011). Worlding Cities : Asian Experiments and the Art of Being Global.Chichester, West Sussex; Malden, MA: Wiley-Blackwell.

[22]. Savitch, H. V. (2010). Rescaling for a global world. Progress in Planning, 73, 11-22.

[23]. Shatkin, G. (2011). Coping with actually existing urbanisms: The real politics of planning in the global era. Planning Theory, 10, 79-87.

[24]. Shen, J. F. (2006). Understanding dual-track urbanisation in post-reform China: Conceptual framework and empirical analysis. Population Space and Place, 12, 497-516.

[25]. Shen, J. F., Feng, Z. Q., \& Wong, K. Y. (2006).Dual-track urbanization in a transitional economy: The case of Pearl River Delta in South China. Habitat International, 30, 690705.

[26]. Sit, V. F. S., \& Yang, C. (1997). Foreign-investment-induced exo-urbanisation in the Pearl River Delta, China. Urban Studies, 34, 647-677.

[27]. Statistics Committee of Chaonan. (2012). Social and Economic Statistical Yearbook of Chaonan District. Beijing: China Statistics Press

[28]. Walder, A. (1995). Local governments as industrial firms: an organizational analysis of China's transitional economy. American Journal of Sociology, 101, 263-301.

[29]. Wang, Y. P., Wang, Y., \& Wu, J. (2009). Urbanization and informal development in China: Urban villages in Shenzhen.International Journal of Urban and Regional Research, 33, 957-973.

[30]. Watson, V. (2002). Do we learn from planning practice? The contribution of the practice movement to planning theory.Journal of Planning Education and Research, 22, 178-187.

[31]. Watson, V. (2009). Seeing from the South: Refocusing urban planning on the globe's central urban issues.Urban Studies, 46, 2259-2275.

[32]. Watson, V. (2013). Planning and the 'stubborn realities' of global south-east cities: Some emerging ideas.Planning Theory, 12, 81-100.

[33]. Wu, F. (2015). Planning for Growth: Urban and Regional Planning in China. London: Routledge. 
[34]. Wu, F. L. (2007). Re-orientation of the city plan: Strategic planning and design competition in China. Geoforum, 38, 379-392.

[35]. Wu, F. L., \& Zhang, J. X. (2007). Planning the competitive city-region-The emergence of strategic development plan in China.Urban Affairs Review, 42, 714-740.

[36]. Xie, Y. C., Batty, M., \& Zhao, K. (2007). Simulating emergent urban form using agentbased modeling: Desakota in the suzhou-wuxian region in China.Annals of the Association of American Geographers, 97, 477-495.

[37]. Xu, J., Yeh, A., \& Wu, F. L. (2009). Land commodification: New land development and politics in China since the late 1990s. International Journal of Urban and Regional Research, 33, 890-913.

[38]. Yang, D. Y. R., \& Wang, H. K. (2008). Dilemmas of local governance under the development zone fever in China: A case study of the Suzhou region. Urban Studies, 45, 1037-1054.

[39]. Yang, Y. A., \& Yu, F. F. (2013). Research on the Urbanization Path in China.Architecture, Building Materials and Engineering Management, pts 1-4, 357-360, 1988-1991.

[40]. Yang, Y. R., \& Chang, C. H. (2007). An urban regeneration regime in China: A case study of urban redevelopment in Shanghai's Taipingqiao area.Urban Studies, 44, 1809-1826.

[41]. Zheng, S. Q., Long, F. J., Fan, C. C., \& Gu, Y. Z. (2009). Urban villages in China: A 2008 survey of migrant settlements in Beijing.Eurasian Geography and Economics, 50, 425-446.

[42]. Zhou, C., Lin, S., \& Dai, D. (2013).Changes of the investment environment in the Pearl River Delta since reform and opening up in China.Tropical Geography, 5.

[43]. Zhou, Y., \& Ma, L. J. C. (2000). Economic restructuring and suburbanization in China.Urban Geography, 21, 205-236.

[44]. Zhu, J. M. (2013). Governance over land development during rapid urbanization under institutional uncertainty, with reference to periurbanization in Guangzhou metropolitan region, China.Environment and Planning C-Government and Policy, 31, 257-275.

[45]. Zhu, J. M., \& Guo, Y. (2014). Fragmented peri-urbanisation led by autonomous village development under informal institution in high-density regions: The case of Nanhai, China.Urban Studies, 51, 1120-1145. 
Table 1 Different types of desakotas

\begin{tabular}{|c|c|c|}
\hline Type & Characteristic & Regions \\
\hline Type I & $\begin{array}{l}\text { Experienced a rapid transformation of the space economy, } \\
\text { although rural areas still retain the original situation, this } \\
\text { space economy is a rapid population transformation from } \\
\text { rural to urban. }\end{array}$ & Tokyo and Seoul \\
\hline Type II & $\begin{array}{l}\text { The regions in these countries have experienced rapid } \\
\text { economic changes during the past } 30 \text { years. (Agricultural } \\
\text { population and agricultural products' proportion of national } \\
\text { production decline, women and old labor are brought into } \\
\text { industrial production) }\end{array}$ & $\begin{array}{l}\text { Four major coastal regions } \\
\text { (Yangtze River Delta, } \\
\text { Pearl River Delta, Beijing- } \\
\text { Tianjin-Tangshan, central } \\
\text { and southern Liaoning } \\
\text { Province) and Taiwan }\end{array}$ \\
\hline Type III & $\begin{array}{l}\text { The situation is similar to Type II in the space and } \\
\text { economy, but the characteristic is the high population } \\
\text { growth and relatively low economic development. }\end{array}$ & Sichuan Basin \\
\hline \multicolumn{3}{|c|}{$\begin{array}{l}\text { Type I and Type II regions both experienced the process of international labor division and global } \\
\text { economic expansion, and the largest cities and transportation nodes in these regions are very } \\
\text { important in the development. }\end{array}$} \\
\hline
\end{tabular}

Source: McGee (1991):12-14 16; Sit and Yang (1997) 
Figure 1 Desakota Spatial System

Sources: Ginsburg.N., The Extended Metropolis, University of Hawaii

Press, $1991: 6$. 
Figure 2 The Mixed-use Landscape in Chaonan 
Figure 3 Planning Paradigm Reconstruction 
Table 2. Output Value and Number of Enterprises of Main Industries in Chaonan (2010)

\begin{tabular}{|c|c|c|c|c|c|c|c|}
\hline Category & Textile & $\begin{array}{l}\text { Daily chemical } \\
\text { industry }\end{array}$ & Stationery & $\begin{array}{l}\text { Printing and } \\
\text { Packaging }\end{array}$ & \multicolumn{2}{|c|}{ Plastic Electronics } & $\begin{array}{l}\text { Industry of the } \\
\text { whole district }\end{array}$ \\
\hline $\begin{array}{l}\text { Output Value (hundred } \\
\text { million) }\end{array}$ & 274.27 & 45.88 & 21.82 & 13.16 & 45.49 & 16.8 & 484.1 \\
\hline Number of enterprises & 2788 & 219 & 97 & 154 & 427 & 127 & 4366 \\
\hline $\begin{array}{l}\text { Percentage of } \\
\text { enterprises (\%) }\end{array}$ & 63.86 & 5.02 & 2.22 & 3.53 & 9.78 & 2.9 & 100 \\
\hline
\end{tabular}


Table 3 : The Industrial Output Value and the Proportion of Chaonan Cluster Total Industrial

\begin{tabular}{ccccc}
\hline Project & Textile clothing & Fine chemicals & Fine chemicals & Industrial output value \\
\hline $\begin{array}{c}\text { Output value } \\
\text { (billion yuan) }\end{array}$ & 72.98 & 23.3 & 10.3 & 142.87 \\
Proportion & $51.12 \%$ & $16.30 \%$ & $7.20 \%$ & $100.00 \%$ \\
\hline
\end{tabular}


Table 4 : The Major Industrial Cluster Enterprises of Chaonan

\begin{tabular}{ccccc}
\hline Project & Textile clothing & Fine chemicals & Fine chemicals & Industrial output value \\
\hline Proportion & $51.82 \%$ & $8.23 \%$ & $5.06 \%$ & $100 \%$ \\
$\begin{array}{c}\text { The number of } \\
\text { enterprises }\end{array}$ & 1076 & 171 & 105 & 2076 \\
\hline
\end{tabular}


Figure 5 Increased Land of Construction from Year 2003 to 2012 
Figure 6 Public-realm enhancement, Plan of Chaonan, MP2013 
Figure 7 Private-sector led projects, Planning of Chaonan, MP2013 
Figure 8 Integrated strategic actions, Planning of Chaonan, MP2013 
Table 5 The comparison of Master Plan 2003 and Master Plan 2013 Master Plan 2003 Master Plan 2013

\begin{tabular}{|c|c|c|}
\hline & Master Plan 2003 & Master Plan 2013 \\
\hline $\begin{array}{l}\text { Planning } \\
\text { Background }\end{array}$ & $\begin{array}{l}\text { The plan focuses on rapid urbanization and } \\
\text { economic development, growth-oriented } \\
\text { local development policies and enterprising } \\
\text { local governance; the plan serves for local } \\
\text { growth marked by land finance; the plan is } \\
\text { "from top to bottom" and serves for the local } \\
\text { government's aim of high-speed } \\
\text { construction. }\end{array}$ & $\begin{array}{l}\text { With self-reflectiveness upon a long- } \\
\text { term and sustainable growth, the plan } \\
\text { begins to turn to scientific development, } \\
\text { people-oriented development, } \\
\text { coordinated development, ecological } \\
\text { low-carbon development, etc. Urban- } \\
\text { rural planning has changed from } \\
\text { 'technological tool' to 'public policy'. }\end{array}$ \\
\hline
\end{tabular}

A rapid growth of local economy

Planning

Guideline

Planning

Process

Planning

Methodology
The process is dominated by the local state, practiced by planning and design groups, with insufficient public participation.

Blueprint planning, highlighting 'technicality', guided by the concept of Urban Growth Supremacism, making spatial plan just from technical perspectives, without a thorough consideration of local contexts.
Concept innovation, ecology development, people-oriented development, embedded development, cultural heritage, urban-rural integration, regional integration

Public participation has been highlighted across the planning process, from planning research, plan making, approve to planning implementation.

Ideal blueprint (not yet)+Action plan: the planning scheme takes account of realistic contexts, including land property rights, local ecological characteristics, local culture, etc.
Target System: strategic target system mainly focuses on high-speed growth; Master Plan: spatial structure plan, land use plan, comprehensive transportation plan, etc.;

Special Plan: tourism plan, municipal Infrastructure plan, etc.
Planning

Content
Target System: the system includes the overall development target as well as social and economic development targets mainly focuses on economic development, social development、

resource utilization, ecological reservation, and cultural preservation; Scenario Plan: Urban-rural integration and spatial development guide, industrial spatial distribution guide, comprehensive land use, regional coordinated development plan, etc.; Special Plan: Historic preservation plan, tourism plan, municipal infrastructure plan, etc.;

Action Plan : Major project distribution plan, short-term development plan, plan implementation guarantee, etc. 


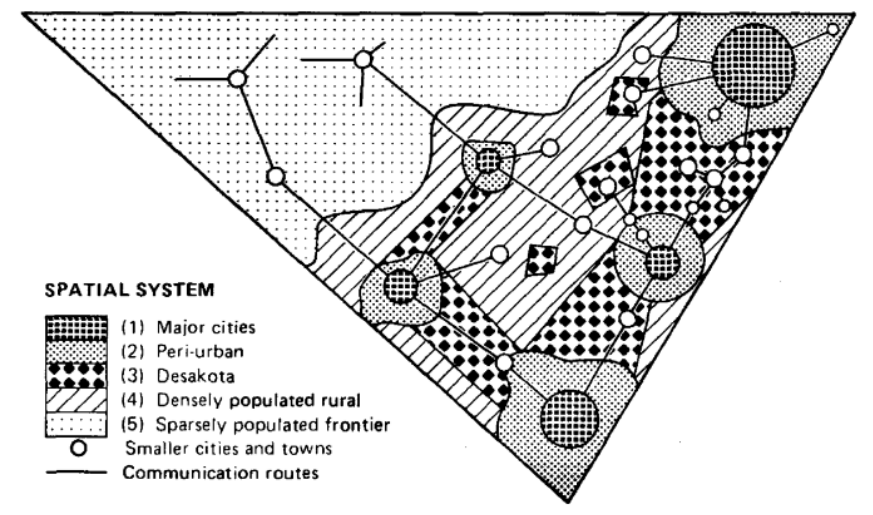

Figure 1 Desakota Spatial System

Sources: Ginsburg-N., The Extended Metropolis, University of Hawaii

Press, 1991: 6 . 

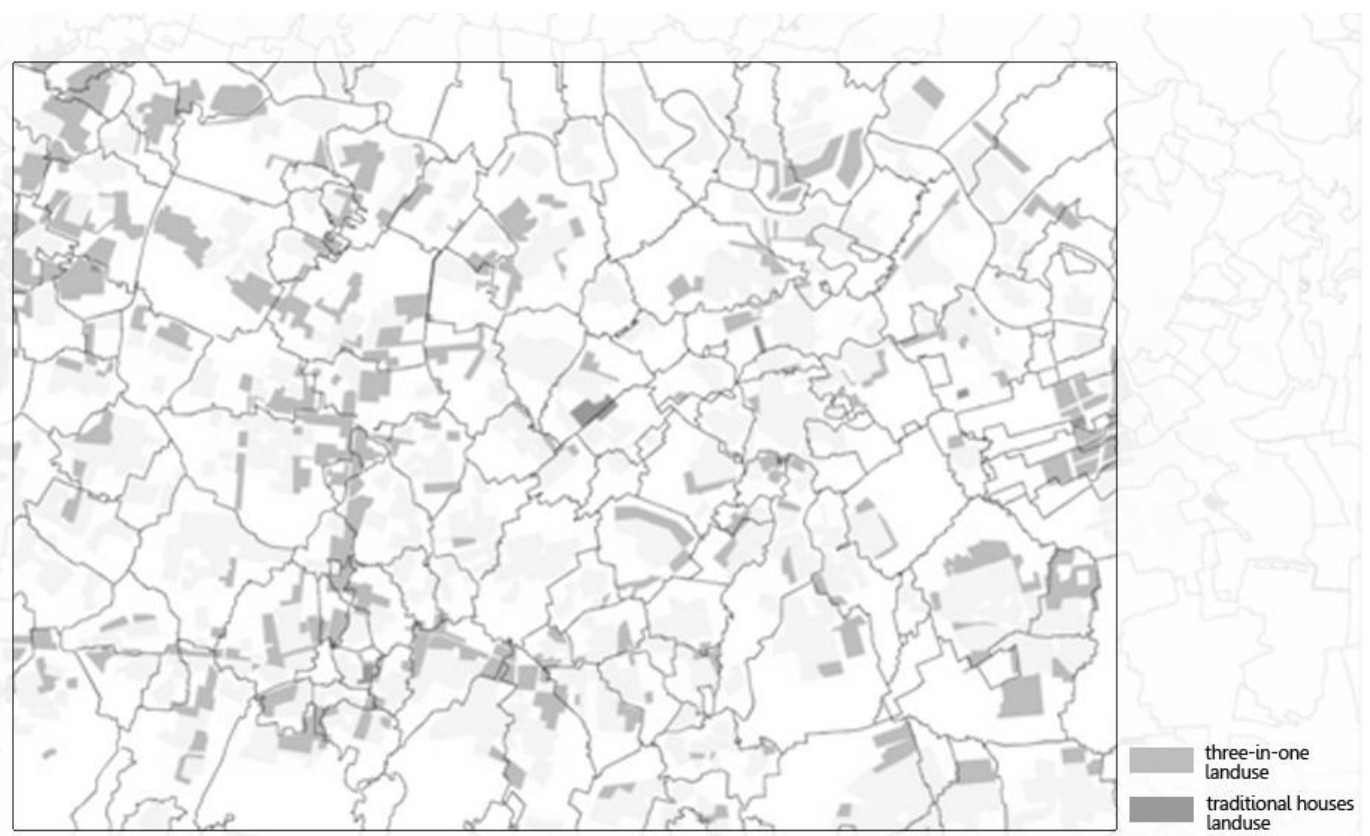

Figure 2 The Mixed-use Landscape in Chaonan 

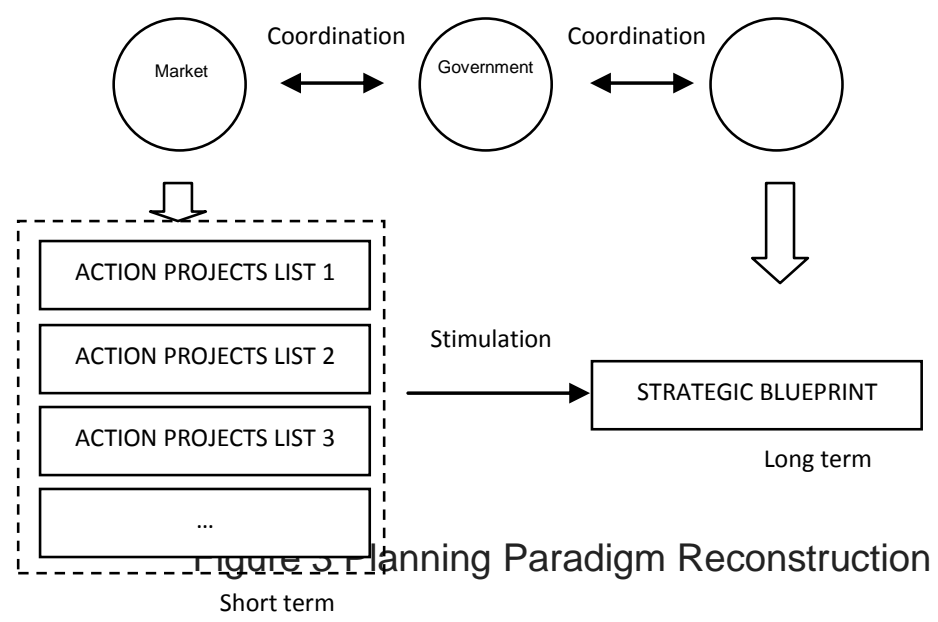


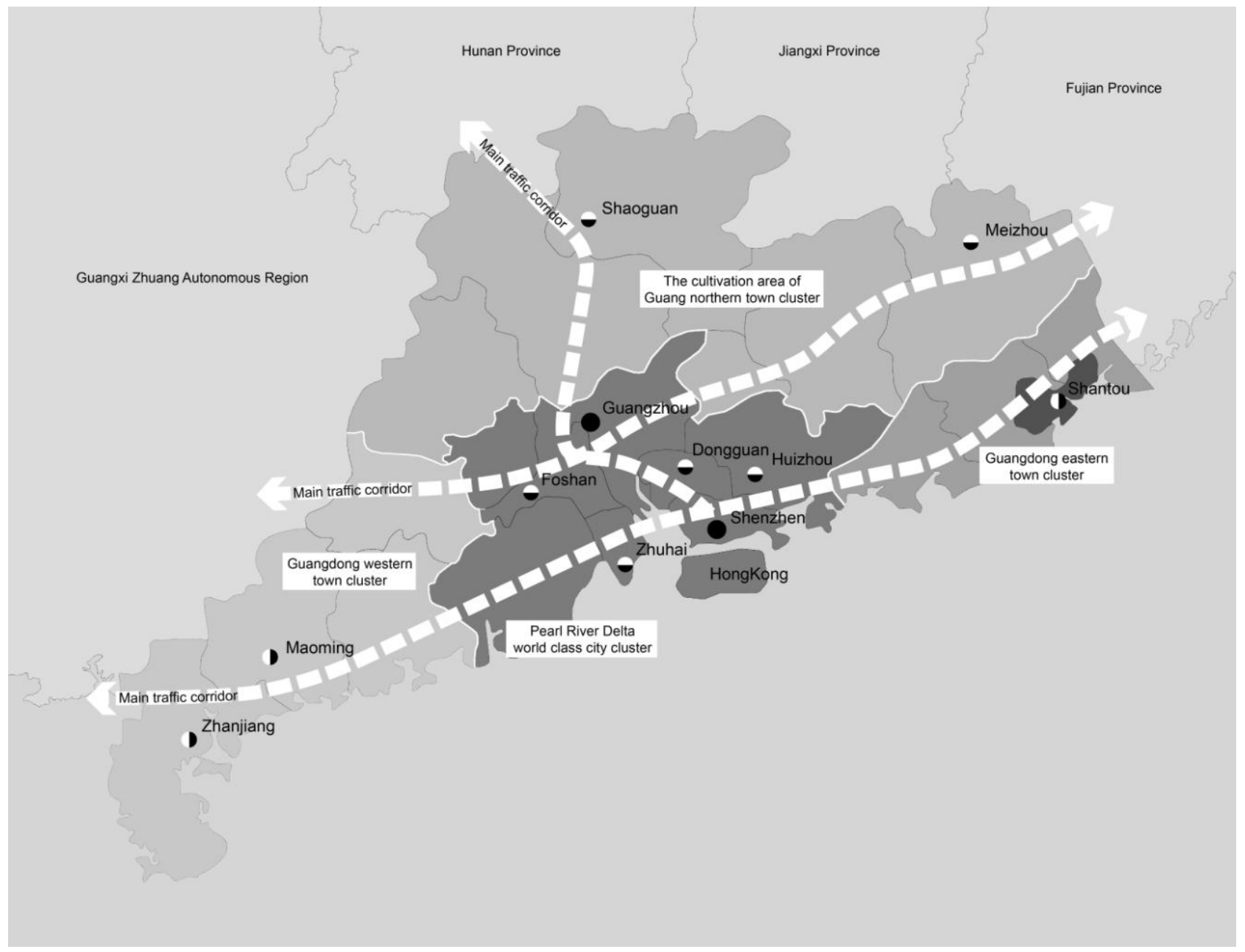




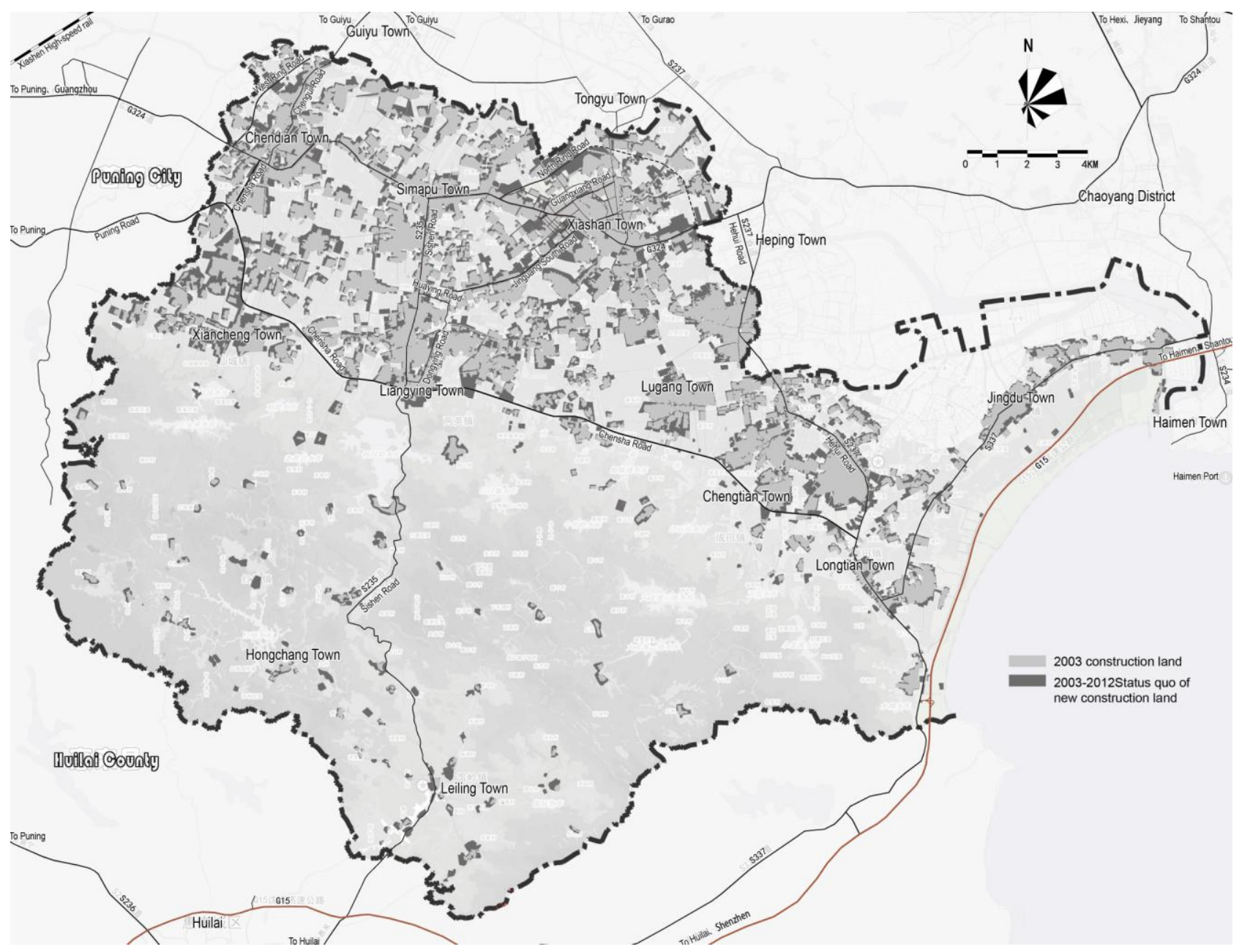




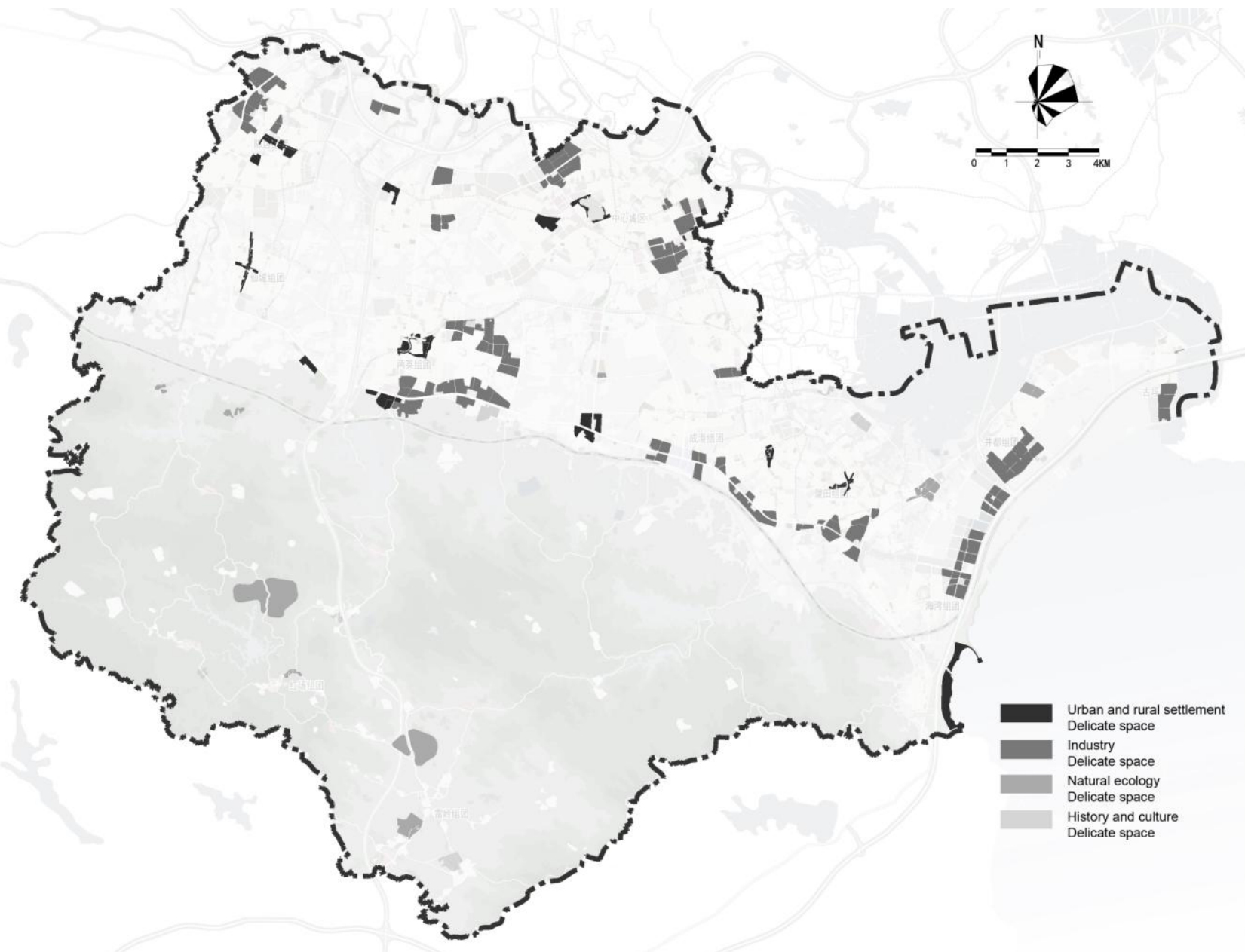




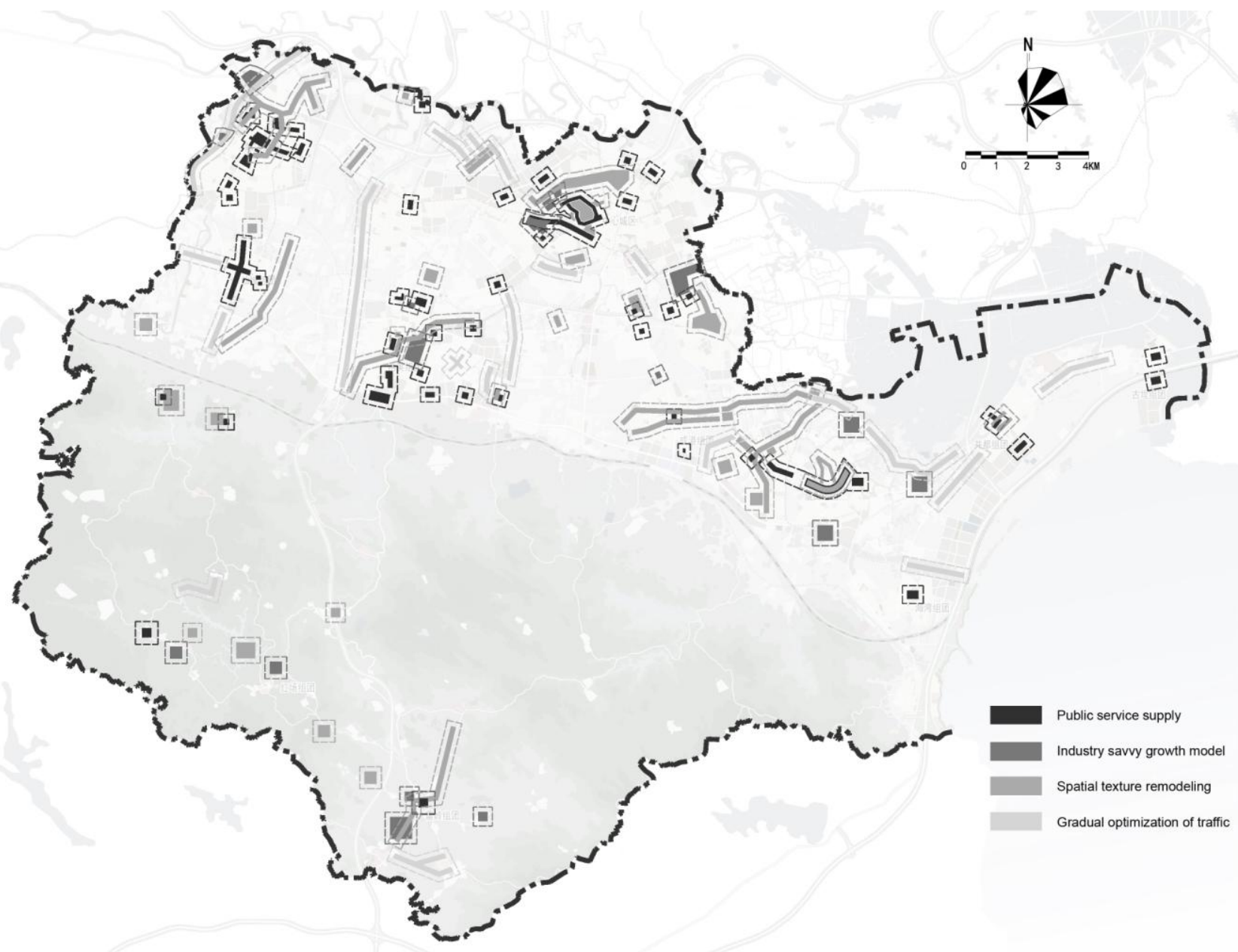




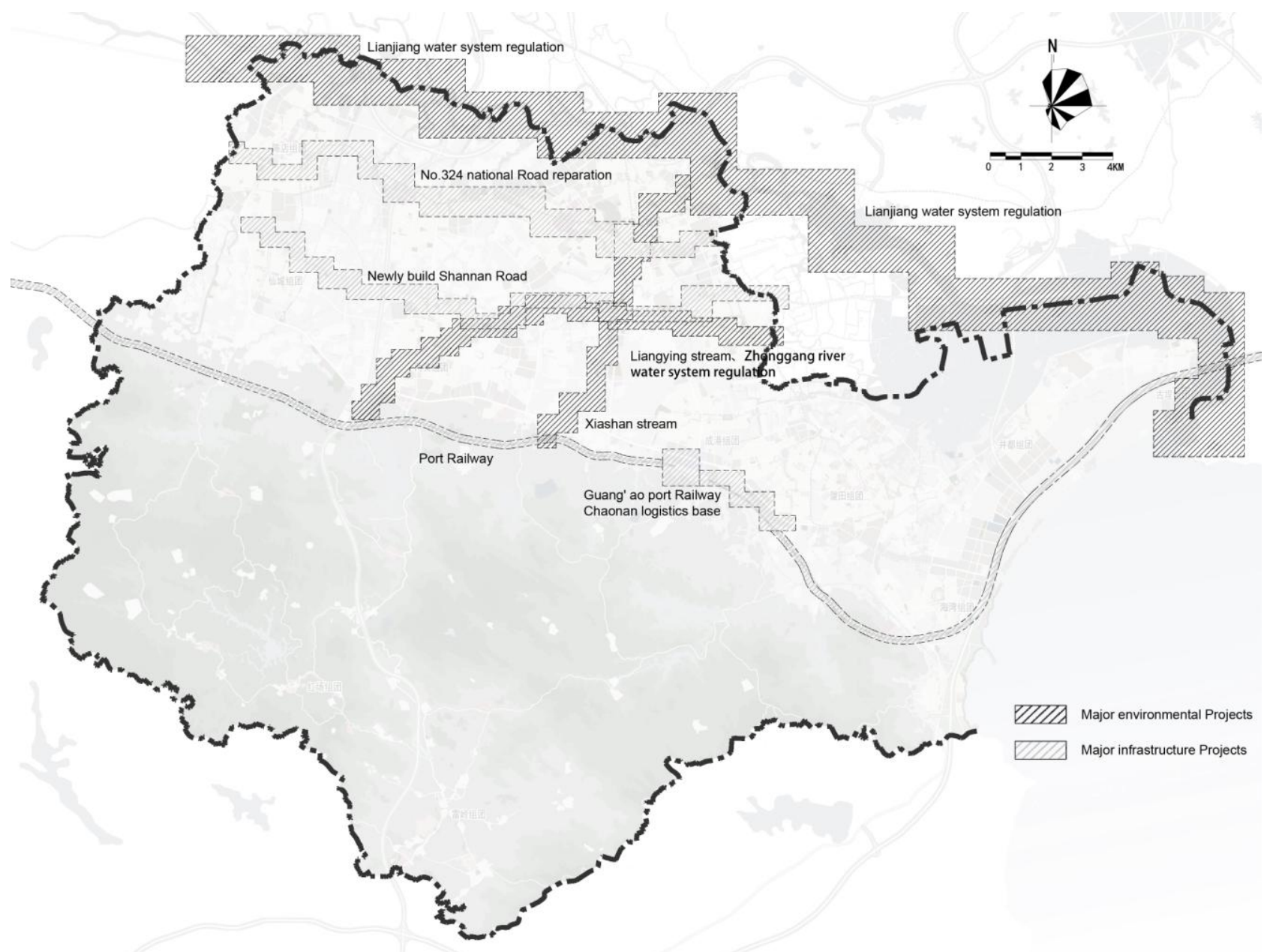

